\title{
Synthesis of electrochemically-reduced graphene oxide film with controllable size and thickness and its use in supercapacitor
}

\author{
Xu-Yuan Peng \\ a,b , Xiao-Xia Liu \\ b,*, Dermot Diamond a, King Tong Lau \\ $\mathrm{a}, *$ \\ ${ }^{\text {a } C L A R I T Y: ~ C e n t r e ~ f o r ~ S e n s o r ~ W e b ~ T e c h n o l o g i e s, ~ N a t i o n a l ~ C e n t r e ~ f o r ~ S e n s o r ~ R e s e a r c h, ~ S c h o o l ~ o f ~ C h e m i c a l ~ S c i e n c e s, ~ D u b l i n ~ C i t y ~ U n i v e r s i t y, ~}$ \\ Glasnevin, Dublin 9, Ireland \\ bChina-Ireland Center for Advanced Materials and Sensor Development, Department of Chemistry, Northeastern University, \\ Shenyang 110004, China
}

\section{A B S T R A C T}

An electrochemical synthesis method of reducing graphene oxide (GO) under constant potential is reported. Electrochemical technique offers control over reaction parameters such as the applied voltage, electrical current and reduction time; whereas the desired size and thickness of the film can be pre-determined by controlling the amount of precursor GO deposited on the electrode with defined shape and surface area. This synthesis technique produces high quality electrochemically reduced GO (ERGO) film with controllable size and thickness. Electrochemical symmetrical supercapacitors based on ERGO films achieved a specific capacitance of $128 \mathrm{~F} / \mathrm{g}$ with an energy density of $17.8 \mathrm{Wh} / \mathrm{kg}$ operating within a potential window of $1.0 \mathrm{~V}$ in $1.0 \mathrm{M} \mathrm{NaNO}_{3}$. The supercapacitor was shown to be stable, retaining ca. $86 \%$ of the original specific capacitance after 3500 charge-discharge cycles. The results indicate that this simple synthesis technique for providing graphene-like materials has great potential in various applications such as energy storage.

\section{Introduction}

The prospect of constructing electronic devices with superconductive, optically clear, mechanically strong and flexible graphene sheets has stimulated researchers to develop different ways to produce graphene or modified graphene materials [1]. Generally, mechanical exfoliation by sonication, thermal exfoliation, epitaxial growth on metal or silicon carbide have been used to produce high quality graphene [2-5]. Chemically synthesized graphene is normally obtained from graphite oxide prepared via Hummers's method, followed by reducing the ultrasonically exfoliated graphene oxide (GO) with hydrazine [6,7]. An alternative method reported involved reacting with sodium metal and ethanol, followed by thermal exfoliation of the intermediate [8]. Electrochemically, a high voltage of $15 \mathrm{~V}$ was used to break down graphite rods into graphene. However, this high potential led to uncontrollable oxidation and structural defects in the resulting graphene sheets [9]. A scanning potential electrochemical method was also employed to reduce GO on a cystamine monolayer modified gold electrode in aqueous electrolyte using a potential window between 0 and $\mathrm{A} 1 \mathrm{~V}$ (vs. SCE) [10]. The difficulty of these methods to produce high quality graphene films for fabricating into technologically viable devices has diverted the attention to chemical vapor deposition or vacuum filtration methods which large graphene sheets or films with controllable thickness could potentially be obtained $[11,12]$. 
Supercapacitors are electrochemical capacitors that have unusually high energy density, typically about two or three orders of magnitude higher than a high capacity electrolytic capacitor. Supercapacitors offer 10-100 times higher power density than batteries, although their energy densities are perhaps $1 / 10$ th that of a conventional battery.

Carbon materials have been studied extensively as electrode materials for supercapacitors. Activated carbon prepared by heating the mixture of petroleum coke and $\mathrm{KOH}$ catalyst in a microwave oven exhibited a specific capacitance of $361 \mathrm{~F} / \mathrm{g}$ in $6 \mathrm{M} \mathrm{KOH} \mathrm{[13].} \mathrm{Porous} \mathrm{carbon} \mathrm{obtained} \mathrm{from}$ chemical vapor deposition of ethylene and acetonitrile on zeolite Y templates showed a high capacitance of $146 \mathrm{~F} / \mathrm{g}$ with tetraethylammonium tetrafluoroborate salt solution in acetonitrile as electrolyte [14]. Bicontinuous ordered mesoporous carbons, fabricated from a KIT-6 template using aluminosilicate as catalyst and furfuryl alcohol as carbon source, exhibited a specific capacitance of $130 \mathrm{~F} / \mathrm{g}$ [15]. Micro/mesoporous carbon electrodes derived from $\mathrm{Mo}_{2} \mathrm{C}$ gave a specific capacitance of $143 \mathrm{~F} / \mathrm{g}$ with $1 \mathrm{M}\left(\mathrm{C}_{2} \mathrm{H}_{5}\right)(3) \mathrm{CH}_{3} \mathrm{NBF}_{4}$ in acetonitrile as electrolyte [16].

Owing to its high specific surface area, graphene has been studied as energy storage material. Stoller et al. fabricated a symmetric supercapacitor based on chemically reduced GO to give a specific capacitance of $135 \mathrm{~F} / \mathrm{g}$ in $\mathrm{KOH}$ and $99 \mathrm{~F} / \mathrm{g}$ in organic electrolytes using a potential window of $1 \mathrm{~V}$ [17].

Wang et al. reported a symmetric supercapacitor based on similar material that gave specific capacitance of $205 \mathrm{~F} / \mathrm{g}$ and a power density of $10 \mathrm{~kW} \mathrm{kgÀ1} \mathrm{in} \mathrm{KOH}$ with similar potential window [18]. Vivekchand and co-workers built a capacitor from a thermal exfoliated GO electrodes to obtain capacitance of $117 \mathrm{~F} / \mathrm{g}$ in $\mathrm{H}_{2} \mathrm{SO}_{4}$ and $75 \mathrm{~F} / \mathrm{g}$ in PYR 14 TFSI [19]. Lin and co-workers electrochemically reduced GO by cyclic voltammetry using a window between À1.0 and $1.0 \mathrm{~V}$ vs. RHE at $50 \mathrm{mV} / \mathrm{s}$ in $\mathrm{Na}_{2} \mathrm{SO}_{4}$ to obtain a material with a specific capacitance of $165 \mathrm{~F} / \mathrm{g}$ using a potential window of $0.9 \mathrm{~V}$ [20]. Chen and co-workers reduced $\mathrm{GO}$ by $\mathrm{NaBH} 4$, and then produced thin film of the chemically reduced GO by vacuum filtration [21]. The capacitance obtained from charge-discharge analysis is $135 \mathrm{~F} / \mathrm{g}$ for a film of approximately $25 \mathrm{~nm}$ in $2 \mathrm{M} \mathrm{KCl}$ electrolyte.

In this paper, a simple, reproducible method to produce graphene films from direct electrochemical reduction of GO is described. This method allows the thickness and size of the graphene film to be pre-determined by the thickness and size of the precursor GO film deposited onto a gold coated polyethylene terephthalate (Au-PET) electrode. The electrochemical reduced graphene oxide (ERGO) produced by this method was demonstrated to be an excellent material for energy storage.
2.2.Preparation of Au-PET substrate and Fabrication of GO film on Au-PET substrate

Gold coated polyethylene terephthalate sheet (Au-PET) was prepared as the electrode substrate for GO film fabrication. The PET was sputter coated with gold using a Polaron SC7640 sputter coater for $10 \mathrm{~min}$ (voltage: $2 \mathrm{kV}$; plasma current: $25 \mathrm{~mA}$ ) at a fixed rate of $10 \mathrm{~nm}$ minà1. Therefore the final thickness of the gold film deposited on the PET substrate was ca. $100 \mathrm{~nm}$.

GO thin film was prepared as following: $10 \mathrm{lL}$ of GO suspension $(20 \mathrm{lg} / \mathrm{mL})$ in Millipore тм water was casted on one end of the gold electrode to cover an area of $4.5 \mathrm{~mm} 2$. The GO film was formed after drying in an oven at $70{ }^{\circ} \mathrm{C}$ for $2 \mathrm{~h}$, with an estimated thickness of around $10 \mathrm{~nm}$, assuming that the density of GO was close to unity. Hence, the thickness of the GO film produced was controlled by the concentration and volume of the GO suspension used to cover electrode of fixed surface area.

\subsection{Electrochemical reduction of $\mathrm{GO}$}

Electrochemical reduction of solid GO film was performed at À1.1 V (vs. $\mathrm{Ag} / \mathrm{AgCl}$ ) in $0.5 \mathrm{M} \mathrm{NaNO}_{3}$ for $4.5 \mathrm{~h}$ by using a $\mathrm{CHI}$ 630 electrochemical analyzer system. A platinum disk electrode and a $\mathrm{Ag} / \mathrm{AgCl}$ electrode were used as the counter and reference electrode, respectively. Electrochemical reduction of GO in suspension was carried out at À1.7 V (vs. $\mathrm{Ag} / \mathrm{AgCl}$ ) with constant mechanical stirring. A gold disk was used as working electrode ( $D=2 \mathrm{~mm}$ ), with a platinum wire and $\mathrm{a} \mathrm{Ag} / \mathrm{AgCl}$ electrode as counter and reference electrodes, respectively.

To investigate the weight loss from GO after electrochemical reduction, the Au-PET substrate was dried in oven under dynamic vacuum at $70{ }^{\circ} \mathrm{C}$ for $24 \mathrm{~h}$ and then measured by analytical balance. $2.0 \mathrm{~mL}$ aliquots of $2.05 \mathrm{mg} / \mathrm{mL}$ GO solutions were used to prepare GO films $(4.1 \mathrm{mg})$ on Au-PET substrate. After reduction, the ERGO film was dried in oven under dynamic vacuum at $70{ }^{\circ} \mathrm{C}$ for $24 \mathrm{~h}$ and then measured by analytical balance. Only $2.9 \mathrm{mg}$ ERGO was obtained after electrochemical reduction, indicating $29.3 \%$ weight loss after reduction due to the removal of oxygen from the film.

\subsection{Chemical reduction of GO}

For comparison, GO in aqueous suspension and as solid film were also reduced chemically using hydrazine according to Stankovich's method (details see S2, Supplementary material) [7].

\subsection{Materials characterizations}

The UV-vis spectra were recorded with a Perkin Elmer Spectrum 900 spectrometer. GO, ERGO, CRGO, and GF were dispersed in Millipore water for measurement. The FT-IR spectra were obtained using a Perkin Elmer Spectrum GX FT-IR system with pure $\mathrm{KBr}$ as the background. GO, ERGO, CRGO, and GF were dried under dynamic vacuum and then ground with $\mathrm{KBr}$ for measurement. Raman spectra were recorded using a Horiba Jobin Yvon LabRAM under a 100.
Graphene oxide (GO) was prepared from graphite flakes (GF) (Aldrich, Product No. 332461) based on Hummers method followed by exfoliation using sonication (details see S1, Supplementary material) [6] 
objective lens and a 632-nm laser. The as-prepared solid GO, ERGO, and CRGO films on Au-PET were dried in an oven at $70{ }^{\circ} \mathrm{C}$ for $2 \mathrm{~h}$ before use. GF were dispersed in Millipore water and then drop-coated on silicon wafer substrates, followed by drying in an oven at $70{ }^{\circ} \mathrm{C}$ for $2 \mathrm{~h}$ before use. AFM images of GO were taken on silicon wafer substrate; ERGO film was prepared on ITO glass substrate for imaging with Nanoscope I AFM instrument from Digital Instruments. The X-ray photoelectron spectra (XPS) measurements were obtained on the Thermo Electron Multilab 2000. All samples were dried in vacuum before XPS investigation.

For conductivity measurements, the electrode substrate was modified so that a ca. $50 \mathrm{~lm}$ insulating gap was created in the middle, along the length of the Au-PET electrode before deposition of the GO film. Hence, the electrical resistance of the coated membrane bridging the two conductive sides could be measured conveniently using a HP 34401A Multimeter before and after reduction.

Electrochemical activities were investigated by cyclic voltammetry in $0.1 \mathrm{M} \mathrm{KCl}$ solution from À1.1 to $0.9 \mathrm{~V}$ at a scan rate of $50 \mathrm{mV} / \mathrm{s}$, using a platinum disk and an $\mathrm{Ag} / \mathrm{AgCl}$ electrode as counter and reference electrode, respectively.

2.6.Investigation of electrochemical capacitive properties of the electrochemical symmetric supercapacitor based on ERGO films

The symmetric supercapacitor was fabricated using two similar ERGO films on Au-PET substrates as anode and cathode with a PVDF filter paper (pore size $=0.2 \mathrm{~lm}$, thickness = $0.17 \mathrm{~mm}$ ) as the separating membrane. Capacitive properties of the supercapacitor were studied by cyclic voltammetry and constant current charging-discharging experiments in $1.0 \mathrm{M} \mathrm{NaNO}_{3}$.

\section{Results and discussion \\ 3.1. Synthesis and characterization}

\subsubsection{Electrochemical reduction of $\mathrm{GO}$}

Aqueous GO suspensions were obtained from chemical oxidation of graphite followed by exfoliation in water (see Section 2 and Supplementary material for details). The inset of Fig. 1 presents a simplified reduction reaction scheme that illustrates the conversion of GO into electrochemically reduced graphene oxide (ERGO). Electrochemical reduction of GO in suspension is limited by the mass transport process. Premature precipitation of partially reduced GO from electrode surface may occur to give product of mixed properties. These disadvantages can be reverted by immobilizing GO onto the electrode surface as a solid film; hence, the reaction kinetics and uniformity of the product is expected to be greatly improved. Critically, this allows the size and thickness of the ERGO film to be pre-defined by the size of the electrode substrate employed and the thickness of the pre-coated GO film. GO forms well dispersed suspensions or solutions due to the presence of hydrophilic acid and carbonyl groups. Hence, many existing self-assembly methods such as vacuum filtration [22], layer-by-layer deposition [23], and interface

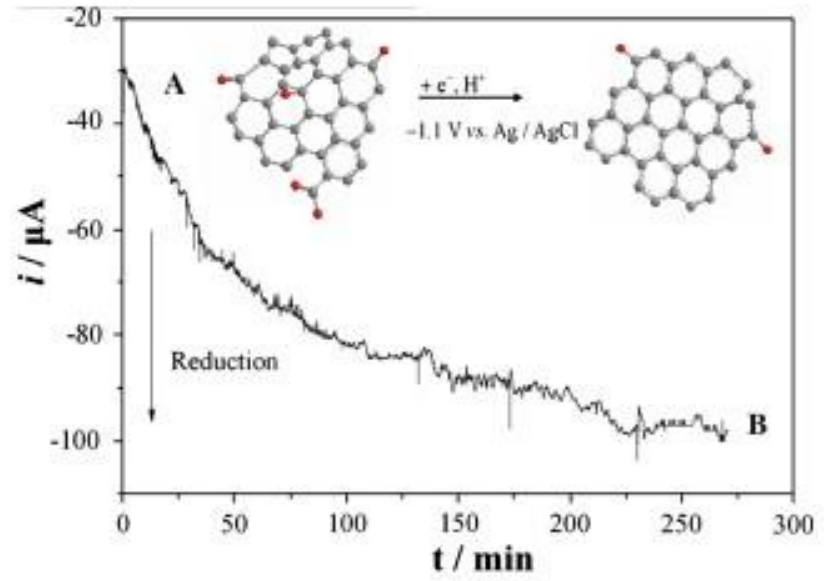

Fig. 1 - (A) The reaction scheme of electrochemical reduction of GO (graphene oxide) to graphene. (B) i À t curve obtained from electrochemical reduction of GO film (weight $=0.2 \mathrm{lg}$ ) at $\mathrm{A} 1.1 \mathrm{~V}$ (vs. $\mathrm{Ag} / \mathrm{AgCl}$ ) in $0.5 \mathrm{M} \mathrm{NaNO}_{3}$ solution.

self-assembly [24,25], etc., can be used to fabricate the uniform precursor GO film. In this work we employed simple solution casting method to deposit GO suspensions of known concentration onto electrode of defined surface area. Therefore it is possible to control the size and thickness of the resulting ERGO film which has properties resembling pristine graphene.

GO films were prepared by casting dilute GO suspension onto gold coated polyethylene terephthalate (Au-PET) electrodes for subsequent electrochemical and chemical reductions. Fig. 1 is the real time electrochemical reduction profile obtained using a constant voltage of À1.1 V vs. Ag/ $\mathrm{AgCl}$. The reduction current increased almost linearly during the first hour before gradually leveling off, indicating the film was becoming more and more conductive during the reduction process until near-equilibrium (reaction completion) was reached. Other workers have also reported electrochemically reduced GO $[20,26,27]$. Shao et al. [20] employed up to 1500 electrochemical redox cycles to produce graphene film from solid GO film. The high number of repetitive reduction and oxidation reactions imposed onto the GO film is expected to produce graphene with more defects within its structure. This can be seen from the of XPS data below. Therefore our product would be essentially different in nature (both chemical and hence physical) from those reported. Physically, our ERGO film was very stable on the substrate and survived many subsequent experiments without peeling off.

The fabrication procedure we had adopted was responsible for the stability of the ERGO film. It is easy to perceive that the self-assembly of the first GO mono-layer on the gold electrode would promote the adhesion of the GO film on the gold surface. The amorphous but polar GO sheets in aqueous suspension deposited on the gold electrode surface naturally lied flat on the gold surface due to their broad and planar configuration. This allowed large area of contact and formed strong electrostatic interactions with the gold surface. On evaporation, more GO sheets stacked onto the first GO layer and were hold together by strong inter sheet electrostatic attraction. Hence, a GO film with strong adhesion on the gold electrode 
was formed. It was impossible to re-disperse a completely dry GO film formed on the gold electrode with ultrasonic bath without destroying (peeling off) the whole gold electrode. In situ electrochemical reduction of the solid GO film restructured the film by removing the oxygenated groups within individual GO sheets. The removal of functional groups at the ERGO and gold interface helped to increase surface contact, hence, further increasing the electrostatic attraction force between the gold and the graphitic film. The removal of the functional groups and the restoration of SP2 carbon also resulted in more compact and stronger film; consequently, a very stable ERGO film was formed.

The weight loss of GO after electrochemical reduction due to removal of oxygen from the film was investigated using gravimetric method and was determined to be ca. $29.3 \%$. This weight loss formed the basis of all subsequent calculations in this work.

\subsubsection{Characterization by X-ray photoelectron spectra} XPS of GO, ERGO, and chemically reduced graphene oxide (CRGO) were investigated. Fig. 2A shows the C1s spectra for GO, CRGO, and ERGO. GO gave a typical broad oxygenated carbon XPS spectrum at $\mathrm{BE}=\$ 286-289 \mathrm{eV}$ with a small carbon peak at $\mathrm{BE}=\$ 283-285 \mathrm{eV}$. Chemically reduced GO shows increased carbon peak with small shoulder representing oxygenated carbon, indicating that incomplete reduction. Electrochemically reduced GO produced by constant potential method gave clean XPS spectrum resembling graphite (not shown); indicating that a complete reduction has been achieved.

Detailed information of the change in chemistry (oxygen containing groups) after reduction obtained from the fitted results of C1s XPS spectra is shown in Table 1. The precursor GO contains $56.44 \%$ of oxygenated carbon including $4.46 \%$ COOR centered around $289.1 \mathrm{eV}, 26.36 \% \mathrm{C} @ \mathrm{O}$ centered around $287.8 \mathrm{eV}$, and $25.62 \% \mathrm{CAO}$ centered around $286.5 \mathrm{eV}[7,20,28]$. After reduction, a total of only $4 \%$ of oxygenated carbon remained in ERGO; whereas $32 \%$ oxygenated carbon had remained in CRGO. Also observed from Table 1 was the effectiveness of $\mathrm{sp}_{2}$ carbon restoration after GO reduction. There are $\$ 49 \% \mathrm{sp}_{2} \mathrm{CAC}$ appeared in the XPS spectrum of ERGO and $\$ 28 \% \mathrm{sp}_{2} \mathrm{CAC}$ in that of CRGO. The XPS spectrum of ERGO does not show any nitrogen N1s line centered at $\$ 400 \mathrm{eV}$. However, a small peak was seen in the spectrum of CRGO, probably due to residue hydrazine. Clearly, constant potential electrochemical reduction is more effective than chemical reduction in producing high quality graphene. Shao et al. [20] have reduced GO film with Nafion as binder using cyclic voltammetry scanning between A 1 and $1 \mathrm{~V}$ for 1500 cycles. The resulting graphene (ER-G) showed an obvious high oxygenated carbon peak $(\mathrm{BE}=286.0-289.0 \mathrm{eV})$ in $\mathrm{C} 1 \mathrm{~s}$ spectrum. The oxygenated carbon content was $\$ 20 \%$; the results are quite similar to those observed from the CRGO reported in this work. These data suggest that constant potential electrochemical technique is superior to cyclic voltametric method for GO reduction. The full-scale XPS spectra of GO, ERGO, and CRGO are shown in Fig. 2b. Very clean spectrum for ERGO and CRGO were obtained, indicating that the graphene obtained is pure and free from other elements except some peaks from the gold substrate. In contrast, the
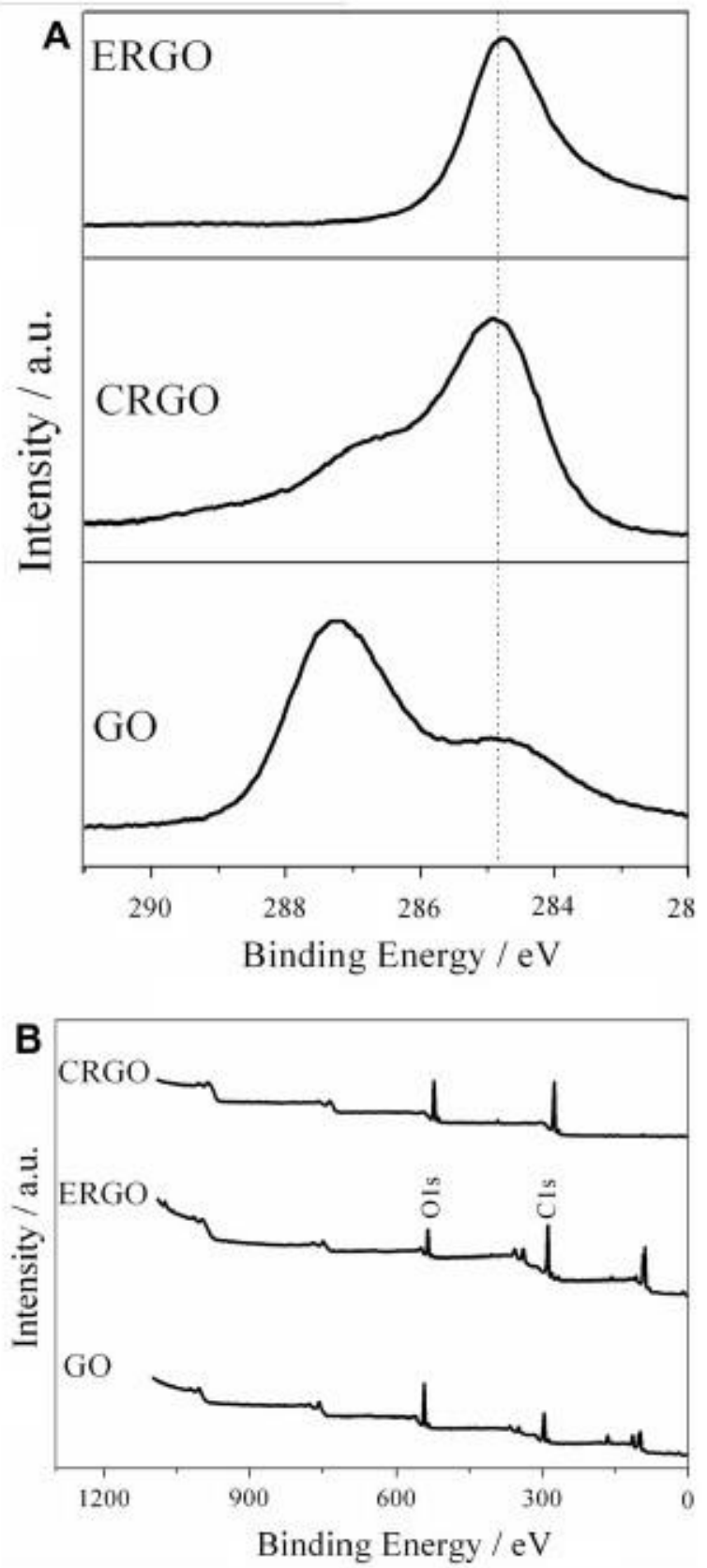

Fig. 2 - (A) C1s XPS spectra of GO, ERGO, and CRGO. (B) XPS spectra of GO, ERGO, and CRGO.

XPS spectra for ER-G showed the presence of high level of binder (signals of the elements $\mathrm{F}, \mathrm{Na}$, and $\mathrm{S}$ from the Nafion binder) in addition to carbon and oxygen [20].

The data presented above indicate that pure, high quality and stable graphene film can be produced using the proposed constant potential reduction method without using binder. It is believed that applying constant voltage allows slow reduction of the GO film over a long period of time until completion without the interruption from the re-oxidation of the film during the positive scans that cyclic voltammetry introduces. This has resulted in more complete reduction to produce better quality graphene film which strongly adheres to the substrate without the need for using a binder. This proposed 
Table 1 - Fitted results (\%) of C1s XPS spectra of GO, ERGO, and CRGO

\begin{tabular}{|c|c|c|c|c|c|}
\hline Sample & $\begin{array}{l}\text { COOR } \\
289.1 \mathrm{eV}\end{array}$ & $\begin{array}{l}\mathrm{C} @ \mathrm{O} \\
287.8 \mathrm{eV}\end{array}$ & $\begin{array}{l}\text { CAO } \\
286.5 \mathrm{eV}\end{array}$ & $\begin{array}{l}\mathrm{CAC}(\text { defect/sp3 }) \\
285.15 \mathrm{eV}\end{array}$ & $\begin{array}{l}\mathrm{CAC}\left(\mathrm{sp}_{2}\right) \\
284.31 \mathrm{eV}\end{array}$ \\
\hline GO & 4.46 & 26.36 & 25.62 & 27.49 & 16.07 \\
\hline ERGO & 0.48 & 0.67 & 3.37 & 46.62 & 48.86 \\
\hline CRGO & 4.00 & 9.01 & 19.03 & 40.01 & 27.95 \\
\hline
\end{tabular}

method for fabrication of graphene film has clear advantages over the existing graphene film fabrication techniques in that stable, pure graphene can be prepared in one step. In applications such as energy storage in supercapacitor, relatively thick films are required; without the use of the proposed method, substantial amount of binding material would need to be used, and subsequently, providing impure material with less ideal properties.

\subsubsection{Characterization by UV-vis spectroscopy}

UV-vis spectra of the as-prepared GO, ERGO and chemically reduced graphene oxide (CRGO) and graphite flakes (GF) suspensions are shown in Fig. S1A. The GO precursor showed a strong absorption band at ca. $230 \mathrm{~nm}$, corresponding to the $\mathrm{p}$ ! $\mathrm{p}$ t transition of aromatic CAC bonds, and a weaker broad shoulder covering ca. 300-400 nm due to the C@O carbonyl $\mathrm{n}$ ! $\mathrm{p} *$ transition, which gives its characteristic yellow color. After reduction, the peak intensity at $230 \mathrm{~nm}$ for both ERGO and CRGO were greatly reduced and the broad absorption band at $300 \mathrm{~nm}$ disappeared, indicating the $\mathrm{C} @ \mathrm{O}$ groups were effectively reduced $[29,30]$.

\subsubsection{Characterization by FT-IR spectroscopy}

The FT-IR data for the GO, ERGO, CRGO, and GF are shown in Fig. S1B. Typical absorption bands observed for GO were: a C@O carbonyl stretching at $1737 \mathrm{cmÀ1}$, a CAO stretching at around $1101 \mathrm{cmÀ1}$ and a broad band at around $1588 \mathrm{~cm} \dot{1} 1$, which was probably due to vibrations arising from adsorbed water molecules overlapping with skeletal vibrations of unoxidized graphitic domains [31]. Other absorption bands included skeletal stretching at $1438 \mathrm{cmÀ} 1$ and aromatic CAH bending at 588 and $729 \mathrm{cmÀ}$. After electrochemical reduction, the carbonyl band of the ERGO disappeared almost completely, accompanied by an increase in the CAO stretching at $1101 \mathrm{cmÀ1}$, this clearly indicating that the GO carbonyl groups had been reduced to hydroxyl groups. The disappearance of the $\mathrm{CAH}$ bands was also significant and might be used as an indication for the conversion of $\mathrm{sp}_{3}$ hybridization into $\mathrm{sp} 2$ hybridization. Chemically reduced GO produced similar IR spectrum, but with a much stronger CAO band, suggesting a higher hydroxyl group density remained in the structure after reduction.

\subsubsection{Characterization by Raman spectroscopy}

Raman spectra (Fig. S2) show the usual D and G peaks for GO around 1331 and $1580 \mathrm{cmÀ}$. The D peak intensity increased with respect to the $\mathrm{G}$ peak for both ERGO and CRGO, indicating that the reduction processes resulted in a higher degree of structural disorder. Using the width of $2 \mathrm{D}$ peaks, the number of layers in the ERGO film was estimated to be around 5, with the CRGO film slightly thicker at around 7-8 layers (Table S1)
$[32,33]$. According to Graf et al., single layer and double layer graphene has a 2D peak width of $\$ 30$ and $\$ 60 \mathrm{cmÀ} 1$ respectively; whereas peak width of $\$ 100$ cmà 1 would be expected for up to six layers. It is quite clear from the data presented in the table that the precursor GO films contained double layers. Stacking occurred during the reduction processes that resulted in ERGO with higher number of layers. The intensity of the G/D ratio was also used to indicate the number of layers [29]. Typically, a ratio of $<0.8$, indicates that the number of layer is <6. The data obtained for the ERGO sample is 0.64 (Table S1), suggesting that the graphene obtained from our procedures was only a few layers thick. An SEM image of ERGO film on Au-PET is also shown in Fig. S3.

\subsubsection{Characterization by AFM}

Fig. 3A is an AFM image of the ERGO film prepared on ITO substrate. The surface roughness and film thickness can be obtained from the height profiles shown in Fig. 3B to be approximately $\pm 5 \mathrm{~nm}$ and $15 \mathrm{~nm}$, respectively. The film thickness observed clearly indicates that the film was composed of overlaying multi-layer ERGO sheets. The number of overlaying ERGO sheet can be estimated from the thickness of precursor GO sheet. Fig. 4 shows an AFM image of a single GO sheet of around $1.2 \mathrm{~nm}$ thick. This is in-line with the predicted effective single sheet thickness for GO of around $1.4 \mathrm{~nm}$, due to the $\mathrm{H}$-bonded water molecules and its intrinsic structural defect $[3,7]$. Therefore, the ERGO film is estimated to consist of approximately 10 layers of individual ERGO sheets.

\subsubsection{Electrical resistance measurements}

It is expected that the conductance of the GO film will be drastically improved after the reduction reactions due to the formation of new electronic conducting pathways via elimination of the carbonyl functional groups and the recovery of $\mathrm{sp}_{2}$ hybridization. This hypothesis was clearly demonstrated by the fact that the insulating GO membrane became highly conductive after the reduction. In general, chemical reduction method produced graphene film (CRGO) $\$ 5$ times more resistive than ERGO, giving an average resistance $(n=3)$ of $293 \mathrm{X} /$ square for CRGO and $65.7 \mathrm{X} /$ square for ERGO, respectively measured across a $\$ 50 \mathrm{~lm}$ gap (Table 2). This discrepancy might be due to better film structure from electrochemical reduction method which eliminated the need to transport reducing agent through the film during the chemical reduction process.

\subsubsection{Electrochemical activities}

The cyclic voltammograms of GO, ERGO and CRGO in $0.1 \mathrm{M}$ $\mathrm{KCl}$ solution are shown in Fig. 5. A distinctive redox couple was observed for the GO with peaks at 0.509 and $0.105 \mathrm{~V}$ (vs. 

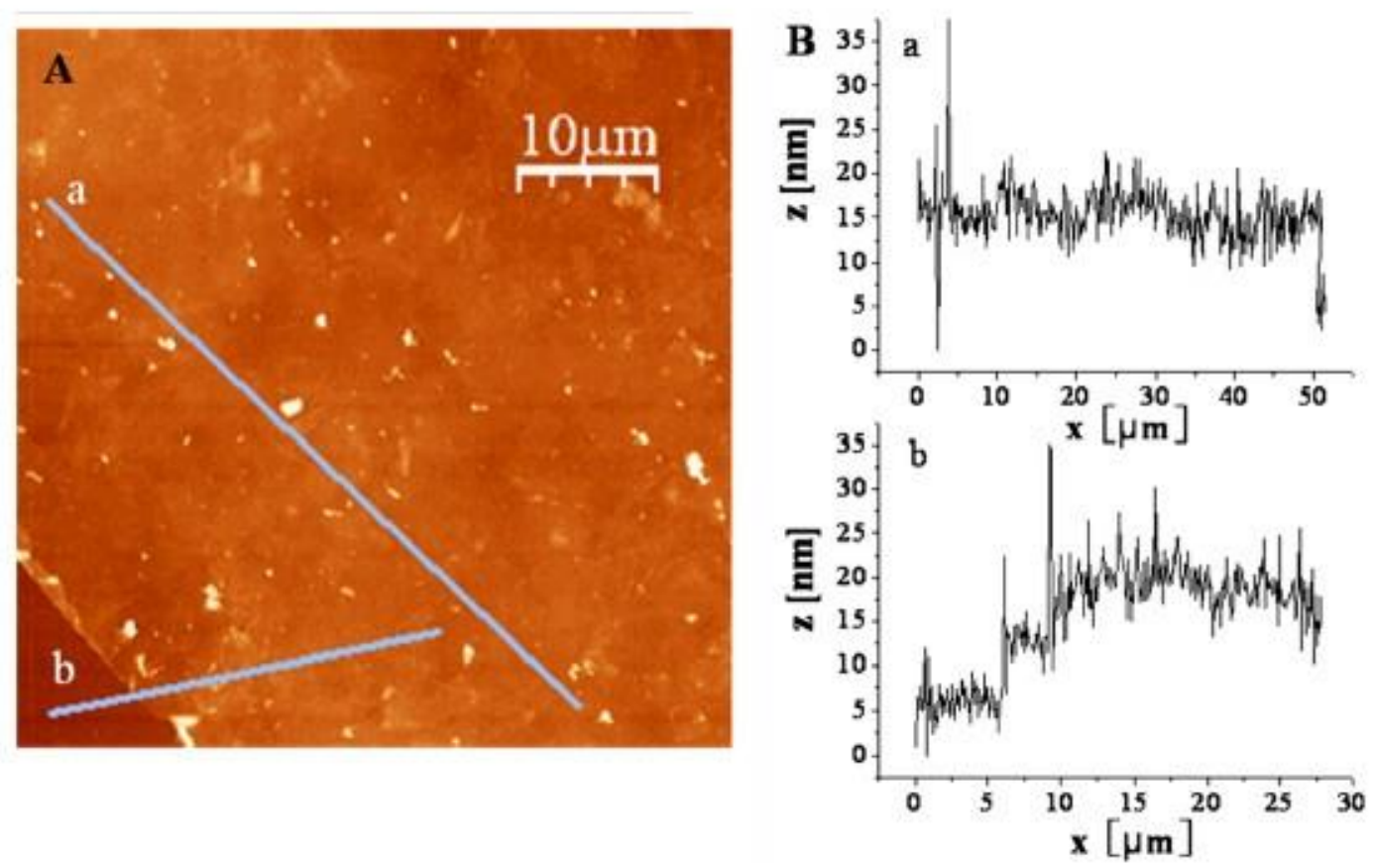

Fig. 3 - (A) AFM image of ERGO film on ITO glass substrate. (B) The height profiles of the ERGO film shown in (A) along the blue lines a and $\mathrm{b}$ showing surface roughness of ca. $\pm 5 \mathrm{~nm}$ and film thickness of ca. $15 \mathrm{~nm}$, respectively.
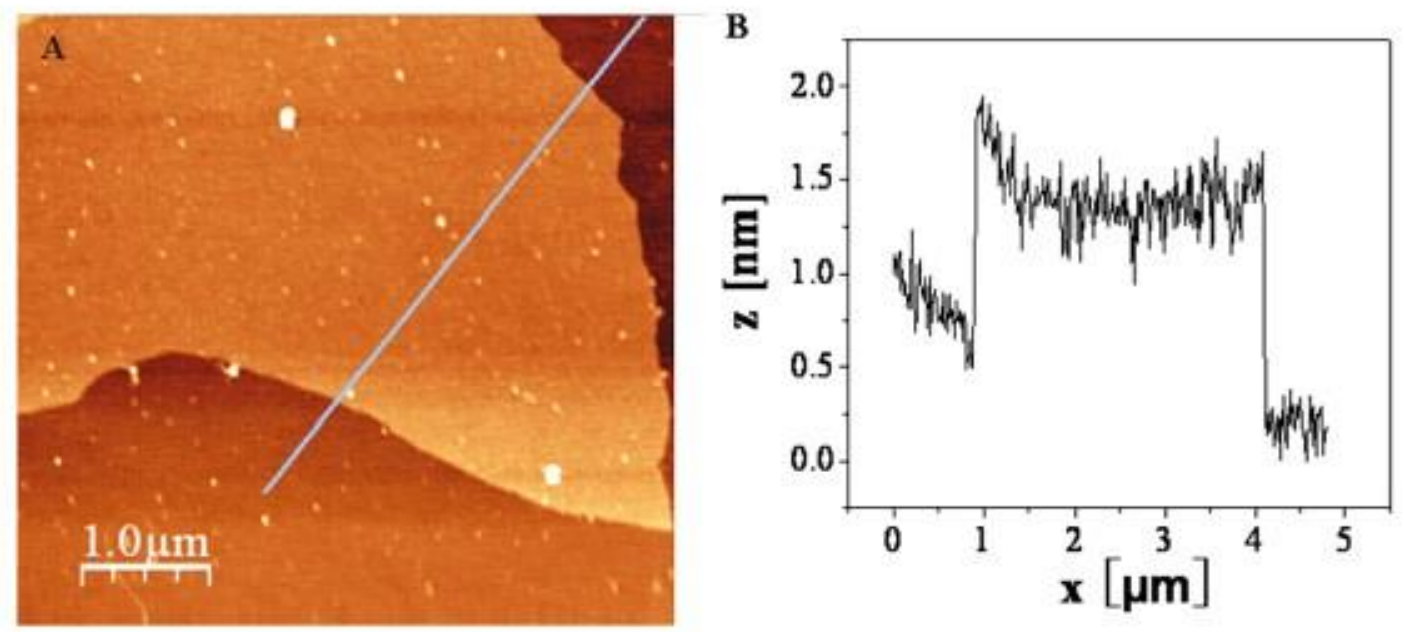

Fig. 4 - (A) AFM image of a precursor GO sheet. (B) The height profile along the blue line in (A) showing sheet thickness of ca. $1.2 \mathrm{~nm}$.

\begin{tabular}{|c|c|c|c|c|}
\hline \multirow[t]{2}{*}{ Films } & \multicolumn{3}{|c|}{ Measured resistance (X/square) } & \multirow{2}{*}{$\begin{array}{l}\text { Average } \\
\text { (X/square) }\end{array}$} \\
\hline & R1 & $\mathrm{R} 2$ & R3 & \\
\hline ERGO & 66 & 63 & 68 & $65.7 \pm 2.5$ \\
\hline CRGO & 415 & 325 & 343 & $361 \pm 47.6$ \\
\hline
\end{tabular}

$\mathrm{Ag} / \mathrm{AgCl}$ ) (Fig. 5c). These peaks most likely to be arisen from aromatic quinone-hydroquinone type transformations. After reduction, this redox couple disappeared completely both in CRGO and ERGO (Fig. 5a and b), indicating that these electro- active (aromatic ketone) groups were converted into nonelectroactive species, probably hydroxyl groups. These data compliment the UV-vis and IR data presented above, which showed the disappearance of carbonyl groups after reduction, associated with an increase in the number of hydroxyl groups in the graphitic structure. The more negative redox couple at À0.148 V and À0.304 V (vs. Ag/AgCl) in GO (Fig. 5c) remained but shifted slightly to more negative potentials after reduction (Fig. $5 \mathrm{~b}$ and c). These peaks could be due to the hydroxide formation on the gold substrate.

The capacitive properties of ERGO film was investigated by chronopotentiometry (CP) in $1.0 \mathrm{M} \mathrm{NaNO}$. Presented in Fig. 6 is a plot that shows rapid charging and discharging behavior 

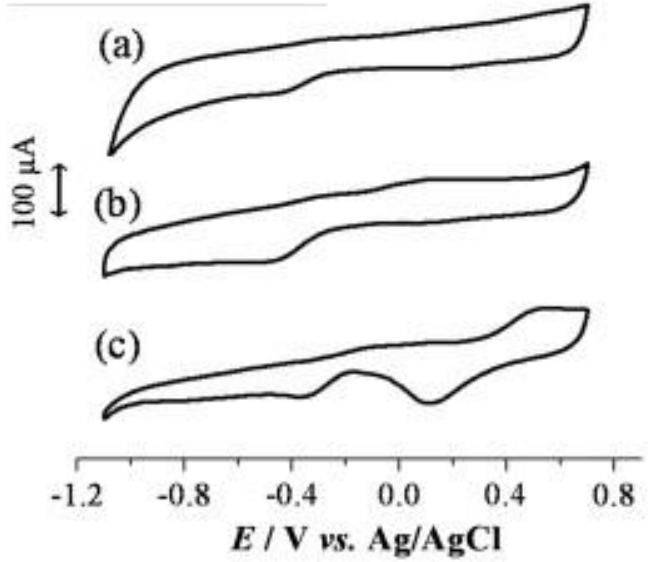

Fig. 5 - Cyclic voltammograms of (a) CRGO, (b) ERGO, and (c) GO films on Au-PET substrates in $0.1 \mathrm{M}$ aqueous $\mathrm{KCl}$ solution at a scan rate of $50 \mathrm{mV} / \mathrm{s}$.

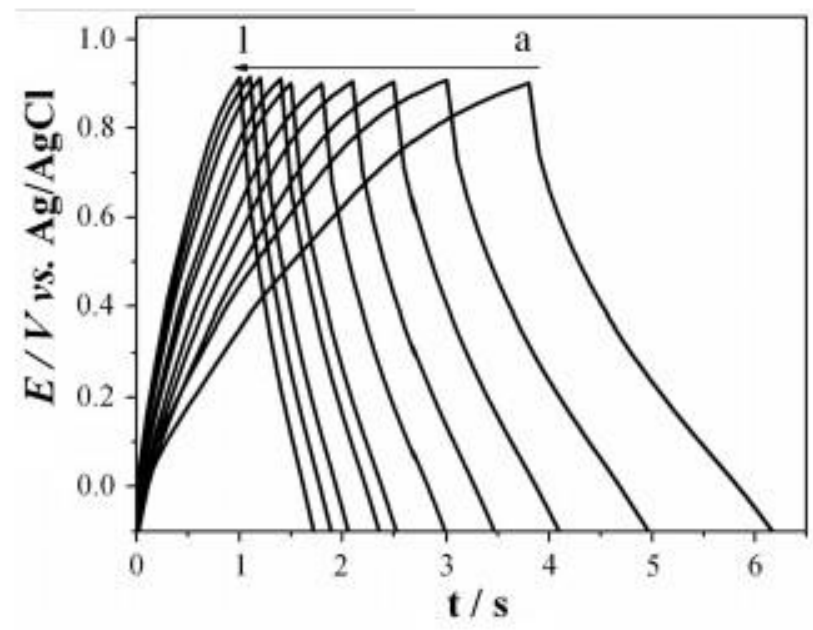

Fig. 6 - Constant current charge-discharge curves of an ERGO film on Au-PET substrate in $1.0 \mathrm{M} \mathrm{NaNO}_{3}$ over potential range between $\grave{\mathrm{A}} 0.1$ and $0.9 \mathrm{~V}$ at current density from 84.86 to $212.16 \mathrm{~A} / \mathrm{g}$.

of ERGO cycling between À 0.1 and $0.9 \mathrm{~V}$ (vs. $\mathrm{Ag} / \mathrm{AgCl}$ ), under a range of applied current density from 84.86 to $212.16 \mathrm{~A} / \mathrm{g}$ $(\mathrm{Di}=14.15 \mathrm{~A} / \mathrm{g})$.

\subsection{Performance of ERGO} pacitor

based symmetric superca-

A symmetric supercapacitor was constructed using two ERGO films separated by a PVDF filter paper. The CV obtained from this electrochemical supercapacitor in $1.0 \mathrm{M} \mathrm{NaNO}_{3}$ at a scan rate of $50 \mathrm{mV} / \mathrm{s}$ (Fig. 7A) shows a rough rectangular shape, which is characteristic of capacitive behavior. Fig. 7B shows the charging-discharging curves measured in potential window of $1.0 \mathrm{~V}$ with a current density of $212.16 \mathrm{~A} / \mathrm{g}$. The specific capacitances $(C)$ and energy $(E)$ and power densities (P) of the supercapacitor were estimated from Eq. (1)-(3), respectively [34]:
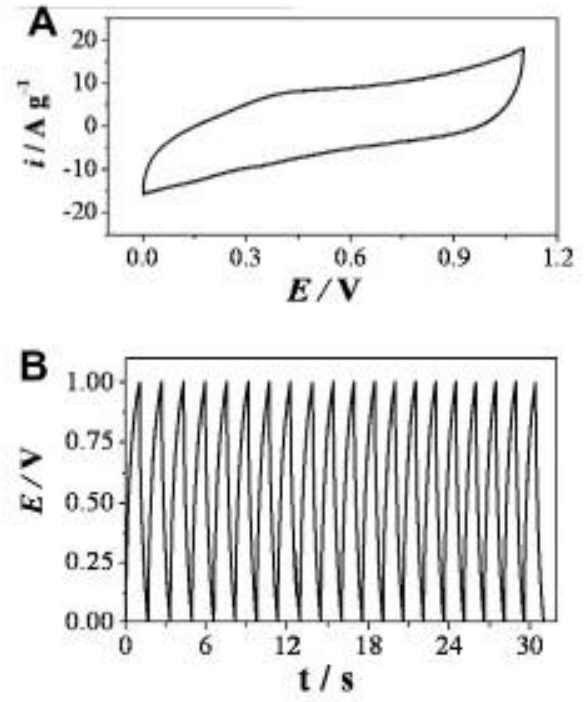

Fig. 7 - (A) Cyclic voltammograms of the symmetrical electrochemical supercapacitor based on ERGO films in 1.0 $\mathrm{M} \mathrm{NaNO}_{3}$ at a scan rate of $50 \mathrm{mV} / \mathrm{s}$ in potential window of 1.1 V. (B) Constant current charge-discharge curves obtained from the supercapacitor in $\mathrm{NaNO}_{3}$ operating at a current density of $212.16 \mathrm{~A} / \mathrm{g}$.

C \% i Á Dt=ðDE Á mP

E 1/4 0:5 Ã C Ã DE2

$\mathrm{P} 1 / 4 \mathrm{E}=\mathrm{Dt}$

where $i$ and Dt are the discharging current density and time, $\mathrm{DE}$ and $\mathrm{m}$ are the discharging potential window and mass of active materials (ERGO) on both electrodes, respectively. The specific capacitance observed for the supercapacitor was $128 \mathrm{~F} / \mathrm{g}$ which is close to those of graphene and other carbon materials reported in the literature [13-21]. The corresponding energy and power density are $17.8 \mathrm{Wh} / \mathrm{kg}$ and 106.08 $\mathrm{kW} / \mathrm{kg}$, respectively.

The ERGO based symmetric supercapacitor displayed excellent stability in potential window of $1.0 \mathrm{~V}$. Fig. 8 illustrates the change in specific capacitance of the symmetric

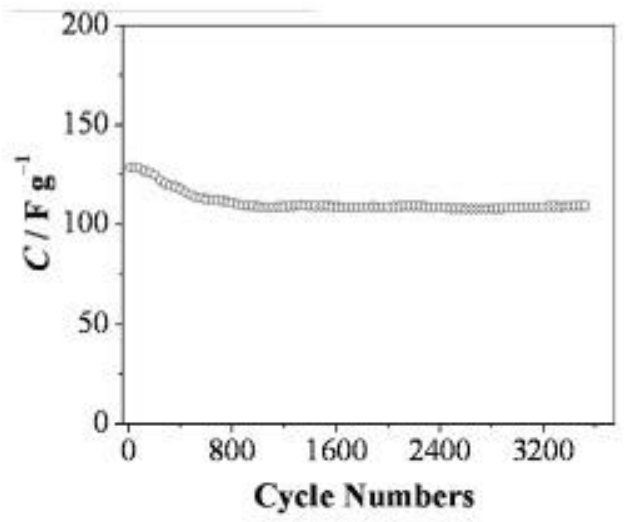

Fig. 8 - The change in specific capacitance of ERGO based electrochemical supercapacitor during a 3500 chargingdischarging cycles operated at $1.0 \mathrm{~V}$ and a current density of $212.16 \mathrm{~A} / \mathrm{g}$ in $1.0 \mathrm{M} \mathrm{NaNO}_{3}$. 
supercapacitor recorded during 3500 continuous cycles. An initial ca. $14 \%$ drop in capacitance after 500 cycles was observed, after that it maintained a very stable capacitance value at ca. $110 \mathrm{~F} / \mathrm{g}$. No obvious lost of activity was observed after the prolong experiment and the device could be reused afterward. This suggests that no film damage or peeling off of the ERGO films from the substrate occurred during the experiment although no binder was used in fabricating the graphene films. The exceptional stability of the proposed supercapacitor was attributed to the specific way the ERGO film was fabricated and the way the supercapacitor assembly was constructed.

Our results have shown that the performance of this proposed supercapacitor is comparable to those recently reported from chemically reduced GO [13-16]. The ERGO based supercapacitor performs well in neutral aqueous salt solutions, providing a highly efficient and environment friendly energy storage system.

\section{Conclusions}

An electrochemical synthesis method has been developed to prepare reduced graphene oxide (RGO) films with characteristics resembling graphene. This simple and versatile technique allows the size and thickness of the desired RGO film to be pre-defined by controlling these parameters when preparing the precursor graphene oxide film. The chemical structure of the ERGO has been characterized and contains alcoholic hydroxyl groups with few carbonyl groups in the graphitic structure. The symmetric supercapacitor fabricated from ERGO films has been demonstrated to be very efficient in energy storage and has excellent stability when operated in neutral $\mathrm{NaNO}_{3}$ electrolyte.

Acknowledgements

We gratefully acknowledge financial support from China Scholarship Council, National Natural Science Foundation of China (50973013), and the China-Ireland Collaboration Funding (co-funded by SFI, RCS and CMOST). The author (K. Lau) also wishes to thank DCU for a Research Fellowship Award. This work is also supported by Science Foundation Ireland under Grant 07/CE/I1 147. We also wish to thank Prof. Tony Cafolla and Prof. Jonathan Coleman for their help with AFM and Raman spectroscopy measurements.

Appendix A. Supplementary data

Supplementary data associated with this article can be found, in the online version, at doi:10.1016/j.carbon.2011.04.047.
[3] McAllister MJ, Li JL, Adamson DH, Schniepp HC, Abdala AA, Jun L, et al. Single sheet functionalized graphene by oxidation and thermal expansion of graphite. Chem Mater 2007;19:4396-404.

[4] de Heer WA, Berger C, Wu XS, First PN, Conrad EH, Li XB, et al. Epitaxial graphene. Solid State Commun 2007;143:92-100

[5] Berger C, Song ZM, Li XB, Wu XS, Brown N, Naud C, et al. Electronic confinement and coherence in patterned epitaxial graphene. Science 2006;312:1191-6.

[6] Hummers WS, Offeman RE. Preparation of graphitic oxide. J Am Chem Soc 1958;80:1339.

[7] Stankovich S, Dikin DA, Piner RD, Kohlhaas KA, Kleinhammes A, Jia YY, et al. Synthesis of graphene-based nanosheets via chemical reduction of exfoliated graphite oxide. Carbon 2007; 45:1558-65

[8] Choucair M, Thordarson P, Stride JA. Gram-scale production of graphene based on solvothermal synthesis and sonication. Nature Nanotech 2009;4:30-3.

[9] Liu N, Luo F, Wu HX, Liu YH, Zhang C, Chen J. One-step ionicliquid-assisted electrochemical synthesis of ionic-liquidfunctionalized graphene sheets directly from graphite. Adv Funct Mater 2008;18:1518-25.

[10] Ramesha GK, Sampath S. Electrochemical reduction of oriented graphene oxide films: an in situ Raman spectroelectrochemical study. J Phys Chem C 2009;113:7985-9.

[11] Kim KS, Zhao Y, Jang H, Lee SY, Kim JM, Kim KS, et al. Largescale pattern growth of graphene films for stretchable transparent electrodes. Nature 2009;457:706-10.

[12] Eda G, Fanchini G, Chhowalla M. Large-area ultrathin films of reduced graphene oxide as a transparent and flexible electronic material. Nature Nanotech 2008;3:270-4.

[13] Liu Y, Wu MQ, Zhang SR. Microwave synthesis of high performance activated carbon electrode material for supercapacitor. Electron Compon Mater 2010;29:28-30.

[14] Portet C, Yang Z, Korenblit Y, Gogotsi Y, Mokaya R, Yushin G Electrical double-layer capacitance of zeolite-templated carbon in organic electrolyte. J Electrochem Soc 2009;156:A1-6.

[15] Li FJ, van der Laak N, Ting SW, Chan KY. Varying carbon structures templated from KIT-6 for optimum electrochemical capacitance. Electrochim Acta 2010;55:2817-23.

[16] Thomberg T, Janes A, Lust E. Energy and power performance of electrochemical double-layer capacitors based on molybdenum carbide derived carbon. Electrochim Acta 2010;55:3138-43.

[17] Stoller MD, Park S, Zhu YW, An JH, Ruoff RS. Graphene-based ultracapacitors. Nanoletters 2008;8:3498-502.

[18] Wang Y, Shi ZQ, Huang Y, Ma YF, Wang CY, Chen MM, et al. Supercapacitor devices based on graphene materials. J Phys Chem C 2009;113:13103-7.

[19] Subrahmanyam KS, Vivekchand SRC, Govindaraj A, Rao CNR. A study of graphenes prepared by different methods: characterization, properties and solubilization. J Mater Chem 2008; 18:1517-23.

[20] Shao YY, Wang J, Engelhard M, Wang CM, Lin YH. Facile and controllable electrochemical reduction of graphene oxide and its applications. J Mater Chem 2010;20:743-8.

[21] Yu AP, Roes I, Davies A, Chen ZW. Ultrathin, transparent, and flexible graphene films for supercapacitor application. Appl Phys Lett 2010;96:253105-1-3.

[22] Dikin DA, Stankovich S, Zimney EJ, Piner RD, Dommett GHB, Evmenenko G, et al. Preparation and characterization of graphene oxide paper. Nature 2007;448:457-60

[23] Kulkarni DD, Choi I, Singamaneni SS, Tsukruk VV. Graphene oxide-polyelectrolyte nanomembranes. ACS Nano 2010;4:4667-76 
[24] Chen CM, Yang QH, Yang YG, Lv W, Wen YF, Hou PX, et al. Self-assembled free-standing graphite oxide membrane. Adv Mater 2009;21:3007-11.

[25] Yuan B, Zhu T, Zhang ZX, Jiang ZY, Ma YQ. Self-assembly of multilayered functional films based on graphene oxide sheets for controlled release. J Mater Chem 2011;21:3471-6.

[26] Zhou M, Wang YL, Zhai YM, Zhai JF, Ren W, Wang F, et al. Controlled synthesis of large-area and patterned electrochemically reduced graphene oxide films. Chem Eur J 2009;15:6116-20.

[27] Guo HL, Wang XF, Qian QY, Wang FB, Xia XH. A green approach to the synthesis of graphene nanosheets. ACS Nano 2009;3:2653-9.

[28] Shao YY, Yin GP, Zhang J, Gao YZ. Comparative investigation of the resistance to electrochemical oxidation of carbon black and carbon nanotubes in aqueous sulfuric acid solution Electrochim Acta 2006;51:5853-7.
[29] Paredes JI, Villar-Rodil S, Martınez-Alonso A, Tascon JM. Graphene oxide dispersions in organic solvents. Langmuir 2008;24:10560-4.

[30] Villar-Rodil S, Paredes JI, Martınez-Alonso A, Tascon JMD.

Preparation of graphene dispersions and graphene-polymer composites in organic media. J Mater Chem 2009;19:3591-3.

[31] Stankovich S, Piner RD, Nguyen SBT, Ruoff RS. Synthesis and exfoliation of isocyanate-treated graphene oxide nanoplatelets. Carbon 2006;44:3342-7.

[32] Malard LM, Pimenta MA, Dresselhaus G, Dresselhaus MS Raman spectroscopy in graphene. Phys Rep 2009;473:51-87.

[33] Graf D, Molitor F, Ensslin K, Stampfer C, Jungen A, Hierold C, et al. Spatially resolved Raman spectroscopy of single- and few-layer graphene. Nanoletters 2007;7:238-42.

[34] Hu CC, Li WY, Lin JY. The capacitive characteristics of supercapacitors consisting of activated carbon fabricpolyaniline composites in $\mathrm{NaNO}_{3}$. J Power Sources 2004;137:152-7. 